Royal Netherlands Institute for Sea Research

This is a postprint of:

van Haren, H. (2017). AABW-transport variation and its effect on internal wave motions between top and bottom of the Puerto Rico Trench. Journal of Marine Research, 75(4), 507-529

Published version: https://dx.doi.org/10.1357/002224017821836716

Link NIOZ Repository: www.vliz.be/imis?module=ref\&refid=290682

[Article begins on next page]

The NIOZ Repository gives free access to the digital collection of the work of the Royal Netherlands Institute for Sea Research. This archive is managed according to the principles of the Open Access Movement, and the Open Archive Initiative. Each publication should be cited to its original source - please use the reference as presented.

When using parts of, or whole publications in your own work, permission from the author(s) or copyright holder(s) is always needed. 


\title{
AABW-transport variation and its effect on internal wave motions between top and bottom of the Puerto Rico Trench
}

\author{
by Hans van Haren ${ }^{1,2}$
}

\begin{abstract}
Slow subinertial variations in Antarctic Bottom Water (AABW) are investigated interacting with internal waves and associated turbulent mixing in the Puerto Rico Trench (PRT), northwest Atlantic. Just below the PRT's top at 5,500 m, a deep-sea mooring was deployed for 14 months. Around $6,100 \mathrm{~m}$, the line held a $200 \mathrm{~m}$ long string of 101 high-resolution temperature sensors and a current meter. Around $8,250 \mathrm{~m}$, a similar string held 102 sensors, of which the lowest was $9 \mathrm{~m}$ above the bottom. As was measured with shipborne conductivity-temperature-depth down to 7,150 m, PRT waters are very weakly stratified, with local mean buoyancy frequency equaling 1-1.7 times the semidiurnal tidal frequency. The observations show alternating quiescent and relatively turbulent periods that correspond with relatively cooler and warmer AABW, respectively. Over the $2,100 \mathrm{~m}$ distance between the two temperature strings, only tidal variations significantly correlate with an average phase difference of $90^{\circ}(3 \mathrm{~h})$ for the entire recording period. This suggests a dominant baroclinic rather than a barotropic coupling. During quiescent periods, the vertical internal wave scale is rather small with out-of-phase tidal motions between the two data sets and vertical excursions of $40 \mathrm{~m}$. During turbulent periods, internal wave motions at all frequencies are close to in phase between the two data sets, suggesting fast vertical propagation with excursions exceeding $200 \mathrm{~m}$. Increased subinertial energy levels, probably reflecting trapped internal waves, are found near the bottom during such periods. It is suggested that internal wave turbulence dominates the deep-sea transport of heat and suspended materials over the entire PRT height and possibly beyond.

Keywords: Deep-ocean internal wave breaking, Puerto Rico Trench, Antarctic Bottom Water, highresolution temperature observations, internal wave and large-scale flow coupling
\end{abstract}

\section{Introduction}

With progressing knowledge of the existence of life in the very deep ocean, it is of some interest to understand the physical processes that maintain habitable conditions at depths beyond 6,000 m. Of particular importance is knowledge of turbulent processes for sufficiently rapid supply of nutrients and oxygen from rich to depleted zones. Molecular diffusion is too slow to maintain abundant life. Turbulence is mainly mechanically driven

1. Royal Netherlands Institute for Sea Research (NIOZ), P.O. Box 59, 1790 AB Den Burg, the Netherlands. 2. Corresponding author: e-mail: hans.van.haren@nioz.nl

(c) 2017 Hans van Haren. 
in stably stratified environments like the ocean. Exceptions are free convective areas (e.g., where dense water is formed near the surface). Internal waves are an important mechanical source when they break, mostly at underwater topography (e.g., Eriksen 1982; Thorpe 1987). They may also generate convective mixing under particular conditions, when particle speeds exceed phase speeds (Orlanski and Bryan 1969).

As internal waves depend on the rotation of the earth and on stable vertical density stratification for support, they may vary in space and time on the scales of processes that modify the stratification. For example, mesoscale eddies of $100 \mathrm{~km}$ horizontal and 1,000 $m$ vertical scales can trap near-inertial internal wave energy when rotating anticyclonically (Kunze 1985). When eddies are related to unstable boundary or slope currents that are driven by topographic vorticity variations, the internal wave-eddy interaction will appear at the timescale of the meandering current. Because most boundary currents are baroclinically driven, having lateral extensions of several tens of kilometers that match the internal, baroclinic, Rossby scale of deformation, their vertical extent is usually not beyond several hundreds of meters below the surface. However, Mediterranean anticyclonic eddies also extend across the entire deeper layer (200-3,000 m), with typical horizontal velocities of only 0.05 times those in the near-surface layer that are in phase and nearly constant down to the bottom (Millot, Benzohra, and Taupier-Letage 1997). This specific characteristic could be because of a pressure gradient resulting in surface elevations $O\left(10^{-1} \mathrm{~m}\right)$ that are not fully compensated by a lowering of the pycnocline providing a baroclinic-barotropic coupling (Obaton et al. 2000). In that case, they can modify internal waves to breaking at great depths and generate turbulent mixing in the deep under particular conditions by changing the background vorticity leading to trapping.

Such coupling is suggested to explain 20 and $100 \mathrm{~d}$ periodicities in current meter observations that were seen over 4,000 m vertical extent in the western boundary current off the Bahamas in the Atlantic Ocean (Lee et al. 1990). The shorter $20 \mathrm{~d}$ periodicity is mainly found for the zonal current component at great depths where the deep western boundary current is flowing southeastward. This is opposite to near-surface waters that flow northwestward. The 100 d periodicity fitted a first mode cutoff, zero group velocity, for baroclinic Rossby waves at latitude $26.5^{\circ} \mathrm{N}$ (Lee et al. 1990). As mentioned before, it requires a coupling with barotropic motions to explain its occurrence over the entire water column. Recently, yearlong moored observations from under the same near-surface Antilles Current farther to the south over the Puerto Rico Trench (PRT) demonstrated subinertial periodicities in temperature observations around 6,000 $\mathrm{m}$ (van Haren and Gostiaux 2016). If these deep observations are coupled to the near-surface current, this would imply boundary current effects that may transport materials over considerable vertical distances.

At such great depths, the "very deep western boundary current" changes sign again and flows to the northwest like the near-surface current and meanders as well (Bryan, Böning, and Holland 1995). Below 4,500 $\mathrm{m}$ and in the PRT below 5,500 m, the flow transports the ocean's densest water mass, the Antarctic Bottom Water (AABW), on its journey in the northwest Atlantic. 
Although the general characteristics of AABW are potential temperature of $-0.8^{\circ} \mathrm{C}<$ $\theta<2{ }^{\circ} \mathrm{C}$ and practical salinity of $34.6<S<34.9$ psu (Mantyla and Reid 1983), they are space and time dependent because of mixing with overlying warmer and generally saltier waters. When flowing along topography and when passing through narrow channels between deep-ocean basins, AABW particularly modifies its characteristics. Thus, in the equatorial region the uppermost level of $\mathrm{AABW}$ is characterized by a density anomaly referenced to $4,000 \mathrm{dbar}$ of $\sigma_{4}=45.90 \mathrm{~kg} \mathrm{~m}^{-3}$ and $1.73^{\circ} \mathrm{C}<\theta<1.81^{\circ} \mathrm{C}$, which are found between 3,800 and 4,300 $\mathrm{m}$ in the Guiana Basin (Rhein, Stramma, and Krahmann 1998). In that basin, the lowest potential temperatures observed are $\theta \approx 1.2^{\circ} \mathrm{C}$ at a sill depth of 4,600 $\mathrm{m}$. At the same level, around $7^{\circ} \mathrm{N}$ and $44^{\circ} \mathrm{W}, S \approx 34.8 \mathrm{psu}$.

Along its transport path farther to the northwest of the Guiana Basin, AABW passes north of Puerto Rico with branches toward the Vema Channel and one entering the PRT from the east and following its northern wall (Tucholke 2002). In the PRT, it has the characteristics of $\theta<1.7^{\circ} \mathrm{C}$ and $S \approx 34.875$ psu. A relatively strong stratification is found between 5,000 and 5,500 $\mathrm{m}$ that marks the transition between North Atlantic Deep Water (NADW) above, transported with the southeastward flowing deep western boundary current or western boundary undercurrent, and the northwestward flowing AABW below. The surrounding ocean basins have a depth of approximately 5,500 m, and the Navidad Sill to the west of the PRT reaches up to 5,200 $\mathrm{m}$. At the same depth as the transition in salinity and temperature, a nepheloid layer is observed and attributed to NADW property (Tucholke 2002). It may well be that, interpreting it as an intermediate nepheloid layer, it is transported along isopycnals from the top of the PRT's sidewalls.

Tucholke (2002) describes AABW flowing along the PRT's northern wall, with NADW flowing along its southern wall. However, this suggests the two water masses to flow adjacent to rather than on top of each other, which would imply a density front along the central axis of the PRT. This would give particular exchange characteristics that are different from diapycnal, vertical exchange between overlying waters. The latter is dominated by shearinduced turbulence as shown for AABW plunging into the Romanche Fracture Zone (RFZ) when crossing the Mid-Atlantic Ridge (van Haren et al. 2014). There, largest overturns are observed when tidal shear coincides with the main gravity current shear. Turbulence and conductivity-temperature-depth (CTD) profiling measurements demonstrated equally strong diapycnal mixing to occur when AABW flows over sills near the RFZ exit (Polzin et al. 1996; Ferron et al. 1998; Mercier and Speer 1998). The persistent supply of AABW into the PRT from the east will either eventually spill over the PRT's western edge or diapycnally mix with overlying waters.

As the western half of the PRT is the location of the Milwaukee Deep, Atlantic Ocean's deepest point, sill mixing is not expected to be particularly strong. This is indirectly confirmed as most mixing seemed of the convective type triggered by internal waves as was concluded from high-resolution temperature sensor observations around 6,100 m (van Haren and Gostiaux 2016). 
a)

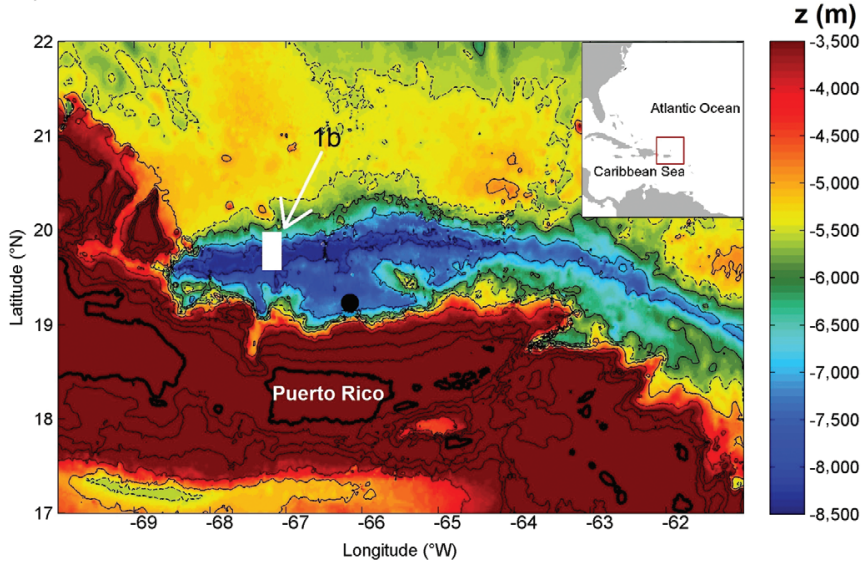

b)

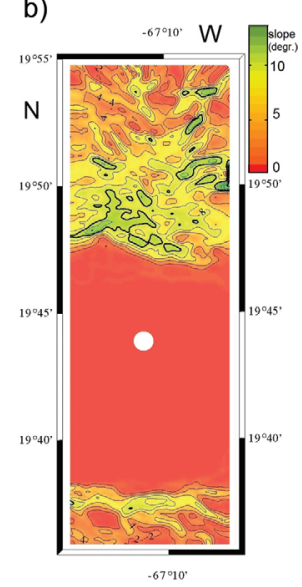

Figure 1. Puerto Rico Trench (PRT) area maps. (a) Bathymetry using the 9.1 ETOPO-1 version of Smith and Sandwell (1997). Solid black contours every 1,000 m; the dashed contour is for 5,500 m, the approximate "top" of the PRT. The white rectangle indicates the area of panel (b), and the black dot the 2013 conductivity-temperature-depth (CTD) site $100 \mathrm{~km}$ from the mooring. (b) Bottom slopes from R/V Pelagia's multibeam system data, with mooring and CTD site indicated by the white dot. Thin contours are drawn every $2^{\circ}$, and heavy contours every $10^{\circ}$.

Here, we elaborate on the interaction between the boundary, AABW-transporting current shearing underneath NADW with internal waves across a vertical range of about $2,000 \mathrm{~m}$ between the top and bottom of the PRT. The aim is to learn more about the coupled nature of the internal waves over this large vertical distance, and with subinertial motions, and its effect on transfer of suspended materials into deep ocean trenches.

\section{Data}

Yearlong moored observations were made in the deepest part of the PRT, at the flat bottom

Figure 1 of the Milwaukee Deep (Fig. 1). On 11 December 2013 (year day 344), the $2.4 \mathrm{~km}$ long mooring was deployed at $19^{\circ} 44^{\prime} \mathrm{N}, 67^{\circ} 11^{\prime} \mathrm{W}$ in 8,370 $\mathrm{m}$ water depth, as determined from R/V Pelagia's Kongsberg EM300 Multibeam using local CTD data for sound profile. The mooring was recovered on 10 February 2015 (year day 770). The foot of the northern wall was $4.5 \mathrm{~km}$ from the anchor weight (Fig. 1b). Typical slopes $\beta$ were between $2^{\circ}$ and $10^{\circ}$, with a mean of $\beta=5.4^{\circ}$ between the foot and $6,000 \mathrm{~m}$. Thus, the top of the mooring was about $30 \mathrm{~km}$ from the northern wall. The mooring had two sections of about $200 \mathrm{~m}$ cable holding 101 and 102 high-resolution temperature sensors between the ranges of [6,004 $6,204] \mathrm{m}$ and $[8,1598,361] \mathrm{m}$, respectively. The lowest sensor was $9 \mathrm{~m}$ above the seafloor. A single Nortek AquaDopp acoustic current meter with pressure sensor was at 6,208 m. As the original planning was to recover the mooring after 10 months, this instrument was programmed to stop registering after 11 months. Buoyancy elements were only at the top 
and consisted of 22 glass spheres, providing nearly $250 \mathrm{~kg}$ net buoyancy. At 3 and $26 \mathrm{~d}$ after deployment, 3 glass spheres, $80 \mathrm{~kg}$ of buoyancy, imploded each time, leaving about $90 \mathrm{~kg}$ net buoyancy. Despite this loss, the top of the mooring did not move more than $1 \mathrm{~m}$ vertically as inferred from the current meter's pressure sensor, except for a few days around days 388 and 675 when current speeds reached a maximum of $0.08 \mathrm{~m} \mathrm{~s}^{-1}$. It never deflected more than $2 \mathrm{~m}$ vertically near the top and presumably a lot less at the lower temperature sensor cable.

The upper temperature sensor cable held NIOZ4 sensors hereafter called "UPP," built from 2010 onward. The lower cable held the older NIOZ3 sensors hereafter called "LOW" (for characteristics, see van Haren et al. 2009). The sensors were spaced at $2.0 \mathrm{~m}$ intervals and sampled at a rate of $1 \mathrm{~Hz}$. They were synchronized via induction every $4 \mathrm{~h}$, so that timing mismatch was $<0.02 \mathrm{~s}$. Their noise level was approximately $10^{-4 \circ} \mathrm{C}$. Because of the long mooring duration, the actual measurement interval of the Wien bridge oscillator was reduced to $50 \mathrm{~ms}$ to save battery power consumption. (The noise floor of $50 \mu \mathrm{K}$ of the sensors is reached when the measurement period is $120 \mathrm{~ms}$.) Of the UPP, 10 sensors showed calibration problems or too high noise levels and were not further considered. The data of the LOW were more difficult, as initially 50 and near the end of the record 70 sensors gave unusable data. Battery problems caused some more sensors to fail with time. However, the largest failure of LOW was attributable to larger drift than the nominal $1 \mathrm{mK}$ per month after aging and pressure effects as the temperature resistors were glued to the glass wall inside the sensor tip. Apparently, the glass deformed slightly under the high static pressure, thereby causing large artificial defects. This is mended in the NIOZ4 by having the resistors free from the wall in thermal grease. However, the titanium housing of the NIOZ4 is rated to $6,000 \mathrm{~m}$, whereas that of NIOZ3 is rated to $12,000 \mathrm{~m}$. Data from bad sensors were linearly interpolated in the vertical. For the single sensor gaps at UPP (cf. van Haren and Gostiaux 2016), this biased turbulence dissipation rate estimates low by about $5 \%-10 \%$, well less than the factor of 2 in estimates' error.

The sensors were calibrated at the Royal Netherlands Institute for Sea Research (NIOZ) using a thermostatic bath with constant temperature levels to within $\pm 10^{-4 \circ} \mathrm{C}$ of their preset values. The standard drift correction was by requiring a smooth statically stable density (temperature) profile for a time section of data of at least the inertial period, in this area nearly $1.5 \mathrm{~d}$, well longer than the buoyancy period so that we can assume static stability. In practice, a period of 4-8 d was taken near or around the period of investigation. (A longer section for correction does not make sense considering the drift.) As the LOW sensors were moored in an environment of 10 times less temperature variance than UPP (see Section 3), they were smoothed over $100 \mathrm{~s}$ intervals to equalize the signal-to-noise ratio between the two data sets in terms of variance. Because all data were obtained in very weak stratification, at the most one-quarter of the adiabatic lapse rate, the electronics drift was first corrected to a constant, homogeneous profile, thereby implicitly correcting for the adiabatic lapse rate. Secondly, the data were transferred to conservative ( $\sim$ potential) temperature $(\mathrm{CT} ; \Theta)$ values (Intergovernmental Oceanographic Commission, Scientific Committee on 
Oceanic Research, and International Association for the Physical Sciences of the Oceans [IOC, SCOR, IAPSO] 2010) by adding constant mean $\Theta$ and $d \Theta / d z$ values from CTD observations. Likewise, GSW software (IOC, SCOR, IAPSO 2010) was used to compute absolute salinity (SA).

For that purpose, three shipborne SeaBird-911 CTD profiles were obtained, two profiles within $1 \mathrm{~km}$ from the mooring site and one profile $100 \mathrm{~km}$ to the southwest. Maximum reachable depths were 7,145 $\mathrm{m}$ in 2013 and 7,107 $\mathrm{m}$ in 2015 because of cable length constraints. These data were also used to establish the local density-temperature relationship for use of the moored UPP data as a tracer for potential density anomaly variations, referenced to $6,000 \mathrm{~m}, \delta \sigma_{6}$. The number of good UPP sensors and the $2 \mathrm{~m}$ resolution were sufficient to use their data to estimate turbulence parameters through the resolution of scales of up to the largest energy-containing Ozmidov scales of turbulence in stratified fluids. Following Thorpe (1977), turbulent kinetic energy dissipation rate $\varepsilon=C_{0}^{2} d^{2} N^{3}$, with $C_{0}=0.8$ a constant (Dillon 1982), and vertical (z) turbulent eddy diffusivity $K_{z}=\Gamma \varepsilon N^{-2}$, with $\Gamma=0.2$ the constant mixing efficiency coefficient for averages over a suitable number of profiles (Osborn 1980; Oakey 1982), were estimated by calculating “overturning displacement" scales $d$ after reordering every potential density (temperature) profile, which may contain inversions, into a stable monotonic profile without inversions. A threshold of $\Delta T_{\text {thres }}=2 \times 10^{-4 \circ} \mathrm{C}$ was used for accepting nonzero overturns. $N$ was computed from the reordered profiles. The estimate of $\varepsilon$ (or, equivalently, the vertical heat flux) was relatively robust and can be made to within a factor of about 2 (van Haren and Gostiaux 2012). These turbulence data were presented in some detail by van Haren and Gostiaux (2016). Unfortunately, the near-bottom LOW sensors were too few and showed too low signal-to-noise ratio for proper turbulence estimating. Density stratification for the near-bottom range was extrapolated from the lowest $250 \mathrm{~m}$ of CTD data. After applying the heavy interpolation, useful LOW information was compared with that from the UPP data.

\section{Observations}

\section{a. CTD data and background internal wave characteristics}

The deep water mass characteristics below 4,500 m are fairly consistent between the two mooring site CTD casts made 14 months apart (Fig. 2). The deviations between the profiles are mainly induced by internal wave motions that show best in layers of largest stratification, around 5,300 m. On the larger vertical scale of $>100 \mathrm{~m}$, both profiles show a monotonous decrease of CT and increase in density anomaly. Less visible in these figures is a weak local SA minimum around 6,600 $\mathrm{m}$. This SA minimum reflects mixing between different water masses. It hardly affects the temperature-density relationship as CT dominates SA in density variations (cf. the approximately equivalent $\mathrm{x}$-axis ranges in Fig. $2 \mathrm{~b}$ and c). The reasonably tight linear relationship $\delta \sigma_{6}=(-0.185 \pm 0.005) \delta \Theta$ (Fig. 2e) is close to the local thermal expansion coefficient, and temperature can be used as a tracer for density variations to estimate turbulence around $6,000 \mathrm{~m}$. In CT, the two profiles are identical to 


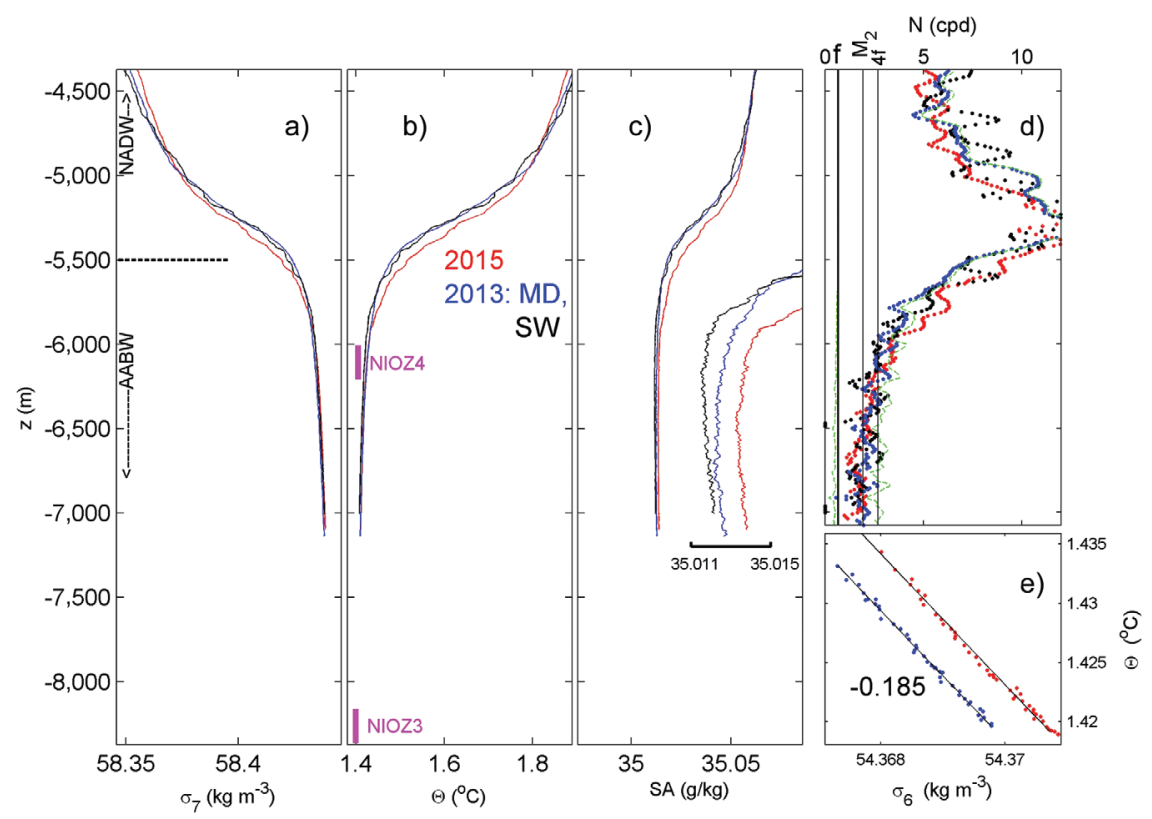

Figure 2. Overview of conductivity-temperature-depth data obtained at $1 \mathrm{~km}$ from the mooring site in the Milwaukee Deep (MD), during the deployment (2013), including a station $100 \mathrm{~km}$ away near the southern wall (SW) (Fig. 1a), and recovery (2015) cruises. (a) Potential density anomaly, referenced to 7,000 dbar. The horizontal dashed line indicates the approximate top of the Puerto Rico Trench or the floor of the surrounding ocean. Approximate main water mass ranges are indicated (see text). (b) Conservative temperature. The vertical bars indicate the ranges of the moored temperature measurements (purple). (c) Absolute salinity (SA). The x-axis range corresponds to that of panel (b) in terms of density contributions. To the right are the lower $1,500 \mathrm{~m}$ multiplied by a factor of 10 and offset horizontally. (d) Buoyancy frequency, smoothed over $100 \mathrm{~m}$. The green dashed lines indicate the minimum $(\leq f)$ and maximum $(\geq N)$ inertio-gravity wave limits for the 2013 blue profile only (see text). (e) Conservative temperature-density anomaly (referenced to 6,000 dbar) relationship for the vertical range of $[5,9006,300] \mathrm{m}$. The slope value is the linear best-fit (negative) apparent thermal expansion coefficient. AABW, Antarctic Bottom Water; NADW, North Atlantic Deep Water.

within $0.1 \mathrm{mK}$ below $6,000 \mathrm{~m}$. However between the two 2013 profiles $100 \mathrm{~km}$ apart, the $\mathrm{CT}$ value is $0.006^{\circ} \mathrm{C}$ warmer at the mooring site for the depth range of $[6,0006,200] \mathrm{m}$ and $0.003^{\circ} \mathrm{C}$ warmer at the mooring site for the depth range of $[6,8007,000] \mathrm{m}$. Extrapolating, a negligible difference is expected near the bottom around $8,200 \mathrm{~m}$. SA values correspond to practical salinity values of $34.840 \mathrm{psu}$.

Although both temperature and salinity contribute to stable density variations below $6,700 \mathrm{~m}$, stratification reaches the lowest values in this range of the CTD profiles: $N(-7,050<z<-6,850 \mathrm{~m})=1.9 \pm 0.4 \mathrm{cpd}=1 \pm 0.2 f_{h}=2.7 \pm 0.6 f$. Here cpd denotes cycles per day; $f=2 \Omega \sin \varphi=0.7 \mathrm{cpd}$, the inertial frequency or vertical Coriolis 
parameter; and $f_{h}=2 \Omega \cos \varphi=1.9 \mathrm{cpd}$, the horizontal component of the earth rotational vector $\Omega$ at latitude $\varphi$. Around $6,000 \mathrm{~m}, N \approx 3.5 \mathrm{cpd}=1.85 f_{h}=5 f$ or nearly twice the value around $6,900 \mathrm{~m}$. Linearly extrapolating to $8,200 \mathrm{~m}$, a conservative estimate is a near-bottom buoyancy frequency of $N \approx 1 \mathrm{cpd}=1.5 \mathrm{f}$, so that the stratification $\propto N^{2}$ differs by a factor of about 10 between the two cables with high-resolution temperature sensors. In such stratification, the traditional approximation (TA) slope $\alpha$ of internal wave characteristics for wave frequencies $\sigma$,

$$
\alpha(\sigma, N, f)=\tan ^{-1}\left[\left(\sigma^{2}-f^{2}\right) /\left(N^{2}-\sigma^{2}\right)\right]^{1 / 2},
$$

is much larger than the bottom slope for semidiurnal lunar tides, $\alpha\left(\mathrm{M}_{2}\right)>>\beta$ for given $N, f$. It is about equal to the mean bottom slope for $\sigma \approx 1.06 f$ around $6,100 \mathrm{~m}$ and for $\sigma \approx 1.01 f$ around $8,200 \mathrm{~m}$. Near the bottom, $\mathbf{M}_{2}$ is not a freely propagating wave frequency, under the TA of range $f<\sigma<N$.

Although the stratification is weak, the water column is not expected to be persistently homogeneous. Nevertheless, the TA cannot be made, and the effects of the horizontal Coriolis parameter need to be taken into account so that inertio-gravity wave (IGW) bounds read for $N=1.5 f$ at 8,200 m and meridional north-south propagation (following, e.g., LeBlond and Mysak 1978; Gerkema et al. 2008) using $2 s=N^{2}+f^{2}+f_{h}^{2}, \sigma_{\min }=$ $\left[s-\left(s^{2}-f^{2} N^{2}\right)^{1 / 2}\right]^{1 / 2}=0.5 f(<f)$ and $\sigma_{\max }=\left[s+\left(s^{2}-f^{2} N^{2}\right)^{1 / 2}\right]^{1 / 2}=2.2 N(>N)$. It implies that from $6,000 \mathrm{~m}$ to the bottom, where the buoyancy frequency changes from $N=5 f$ to $1.5 f, \sigma_{\min }=0.9 f$ to $0.5 f$. Thus, in this depth interval the frequency range of trapped waves is largest at the seafloor, here. For IGW, the dispersion relation reads

$$
\sigma^{2}=N^{2} \cos ^{2} \alpha+\left(f_{h} \cos \gamma \cos \alpha+f \sin \alpha\right)^{2},
$$

where $\gamma$ is the angle to the north and $\gamma=0$ denotes meridional propagation. Different from equation (1), two characteristic slopes emerge per wave frequency,

$$
\alpha_{ \pm}(\sigma, N, f)=\tan ^{-1}\left\{f f_{h} \pm\left[N^{2}\left(\sigma^{2}-f^{2}\right)+\sigma^{2}\left(4 \Omega^{2}-\sigma^{2}\right)\right]^{1 / 2} /\left(N^{2}-\sigma^{2}+f_{h}^{2}\right)\right\}
$$

for $\gamma=0$. For zonal propagation $\gamma=\pi / 2$, equation (1) is retrieved. For weak $N$, the bottom slope is still subcritical for $\mathrm{M}_{2}$ as $\alpha_{ \pm}>\beta$. Near-critical slopes $5^{\circ}<\alpha_{-}<10^{\circ}$ are found for waves at the diurnal frequencies under $1.5 f<N<5 f$. Bottom slopes are supercritical for waves at near-inertial frequencies $0.9 f<\sigma<1.06 f$.

For zonal, east-west propagation the IGW bounds are equal to $f$ and $N$, respectively, as in the TA. The meridional propagation bounds for the 2015 profile are given in green in Figure 2(d). These IGW bounds imply that inertial internal waves propagate freely but no longer strictly horizontally and at an angle to the vertical (see equation 3 ). It also implies that internal tides can propagate through the entire water column, provided they are more and more meridionally propagating as they go deeper where the stratification becomes weaker and the IGW band more limited. 


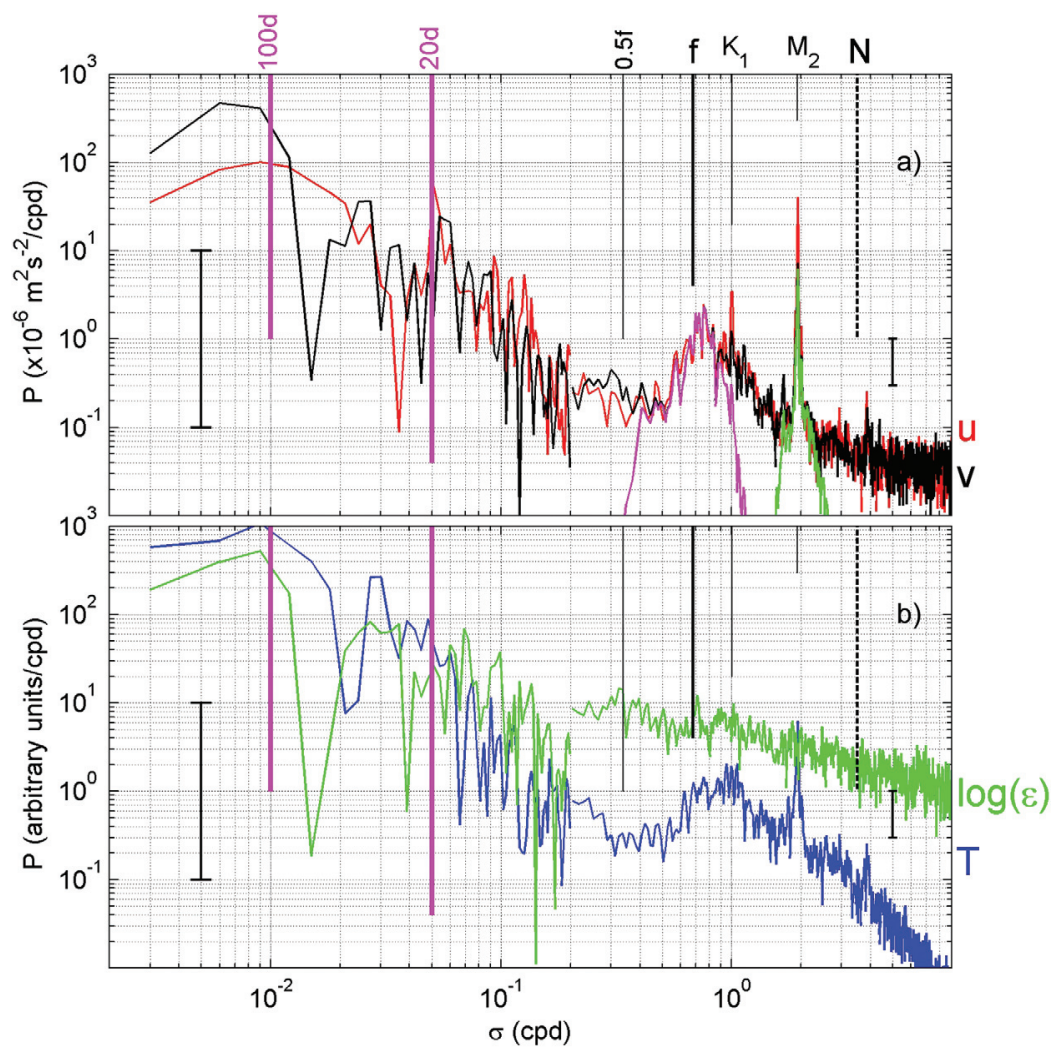

Figure 3. Spectral overview of moored observations around 6,100 $\mathrm{m}$ in the upper level of the mooring and the Puerto Rico Trench waters, where $N$ is observed approximately 1.8 times larger than around $7,000 \mathrm{~m}$. Spectra are weakly smoothed, $\sim 3$ degrees of freedom (dof) for $\sigma<0.2 \mathrm{cpd}$ with $95 \%$ confidence range given to the left, and moderately smoothed, $\sim 15$ dof for $\sigma>0.2 \mathrm{cpd}$ with $95 \%$ confidence range to the right. (a) Zonal current component (red) and meridional current component from $6,208 \mathrm{~m}$ (black). In the $v$ spectrum, two bandpass filters are indicated around the inertial frequency (purple) and the semidiurnal frequency (green). (b) Temperature series from 6,204 m and the logarithm of $200 \mathrm{~m}$ vertically averaged turbulence dissipation rate (green) computed using all 101 temperature sensors between 6,004 and 6,204 m by van Haren and Gostiaux (2016).

\section{b. Upper PRT meridional internal wave propagation and subinertial modulation}

The suggested meridional propagation of internal tides is reflected in the spectra of moored observations around 6,100 m where $N \approx 5 f$ (Fig. 3). For clarity, two different sets of degrees of freedom (dof) are used with a transition at the relative gap with relatively low variance around $\sigma=0.5 f$, the lower IGW bound for the minimum buoyancy frequency estimated. Smoothing is weak at frequencies below that of the gap, by averaging over fewer (longer) windows (i.e., lower dof), and high at higher frequencies, by averaging over more 
(shorter) windows (i.e., higher dof). This relative spectral gap is observed in $u, v$, and $T$, but not in the logarithm of dissipation rate. The latter shows a small bulge around $0.5 f$.

In the IGW "internal wave" band of approximately $0.5 f<\sigma<2 N$, all observed parameters show a tidal peak, except for the turbulence dissipation rate. The latter probably reflects the intermittency of internal wave breaking. At semidiurnal but also at diurnal tidal frequencies, the zonal $u$ component shows 7 times larger variance than the meridional $v$ component. This results in a flattening of the tidal ellipse. Together with the elongation of the long axis in zonal direction (not shown), it indicates a predominant meridional propagation direction (van Haren and Millot 2004). To a much lesser extent, this is also observed for the inertial motions (not shown), which, however, have almost the same variance in $u$ and $v$ and which show only weakly flattened (1.25 ratio) near-circular motions. This is understood as they are closer to the lower IGW bound. It also implies that waters are not homogeneous, in which near-rectilinear inertial motions would be observed (van Haren and Millot 2004). The 1.25 ratio is approximately equal to the theoretical value for $N \sim 2 f$ (Gerkema et al. 2008). The near-inertial propagation direction is more ambiguous, with preference for the meridional direction. As the PRT is almost strictly directed east-west, the near-meridional propagation of the dominant internal waves suggests an influence of the northern and southern walls of the PRT, as a source, a potential sink as wave breaking is most likely occurring for propagation perpendicular to a slope, or both, for them. It is noted that the PRT is not a closed basin with uniquely standing modes. Waves can propagate out into the overlying waters. Besides the elliptical properties given previously, vertical phase differences presented in the next subsections provide further evidence of wave propagation.

In the subinertial range $\sigma<0.5 f$, the $u$ current shows most pronounced peaks at $20 \mathrm{~d}$ and $100 \mathrm{~d}$ periodicities. The $v$ component shows a larger $100 \mathrm{~d}$ periodicity and a weaker 20 $\mathrm{d}$ periodicity, which is also somewhat blue shifted. Temperature and dissipation rate also show their largest variance around $100 \mathrm{~d}$ periodicity, but ambiguous broadening around 20 $\mathrm{d}$ periodicity. This is partially caused by the intermittency of the $20 \mathrm{~d}$ periodicity, occurring mainly in the first $150 \mathrm{~d}$ of the record, while only occasionally reappearing later in the record (e.g., around day 600 and around day 750; Fig. 4). The $20 \mathrm{~d}$ and $100 \mathrm{~d}$ variabilities result in approximately $0.01^{\circ} \mathrm{C}-0.02^{\circ} \mathrm{C}$ changes in temperature (Fig. 4a) and two orders of magnitude changes in vertically and hourly averaged turbulence dissipation rate (Fig. 4b). As observed by van Haren and Gostiaux (2016), the largest dissipation rates are related with relatively warm(ing) waters. Statistically, only temperature over the $200 \mathrm{~m}$ string range and temperature with the logarithm of dissipation rate correlate, in the band of 0.04-0.05 cpd ( $\sim 20$ d periodicity). A correlation between these two parameters and the $0.1 \mathrm{cpd}$ lowpass-filtered subinertial current components in Figure 4(c) is not found significant. This may have to do with the shortness of the yearlong record resulting in a limited number of dof for especially the $0.01 \mathrm{cpd}$ band. It may also have to do with the natural intermittent nondeterministic variability of the subinertial motions that may be modified by, for example, other stratification variations. In the first $150 \mathrm{~d}$ and last $50 \mathrm{~d}$ of current measurements, temperature and dissipation rate visually correspond more or less with $-u_{\mathrm{lf}}$. In between, 


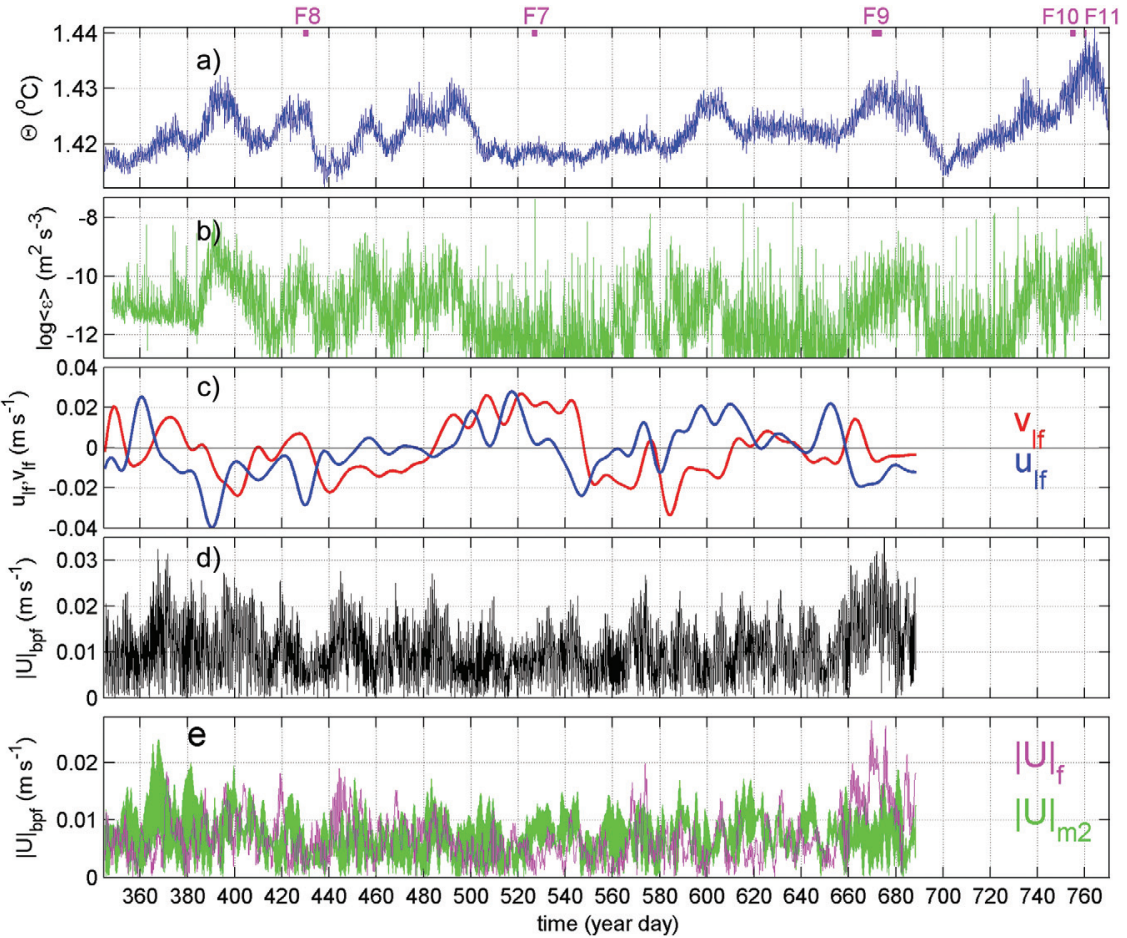

Figure 4. Time series overview of the data in Figure 3, using the same colors, except for the items in panels (c) and (d). (a) Conservative temperature at 6,204 m. Purple bars indicate the periods of Figures 7-11 (F7-F11). (b) The logarithm of the vertically averaged dissipation rate. (c) Subinertial $\sim 0.1$ cpd cutoff low-pass-filtered horizontal current components. (d) Amplitude of combined bandpass-filtered near-inertial and semidiurnal currents combined (see Fig. 3a for the filter cutoff frequencies). (e) Amplitudes of bandpass-filtered near-inertial (purple) and semidiurnal currents (green). Note the difference in vertical scale compared with panel (d).

the reverse gives a better fit. Correspondence is even more variable for the north-south component.

As inertial motions and tides are considered the internal wave (energy) sources, a correlation is expected between their currents and records of temperature and dissipation rate. However, $u$ and $v$ current components correlate strongly at $f$, but only at the semidiurnal tide with $T$. The combined near-inertial and semidiurnal tidal internal wave current amplitudes of $0.01-0.03 \mathrm{~m} \mathrm{~s}^{-1}$ show a dominant $20 \mathrm{~d}$ periodicity of modulation (Fig. 4d), which does not correlate significantly with the temperature and dissipation rate variations. Apparently other, high-frequency or nonlinear, internal waves dominate the latter. Sometimes these records correspond (e.g., around days 480, 560, and 670), sometimes not (e.g., around days 380 and 510). The modulations of semidiurnal tides and inertial motions generally alternate their amplitudes, which vary between 0.005 and $0.025 \mathrm{~m} \mathrm{~s}^{-1}$, tides being larger when 


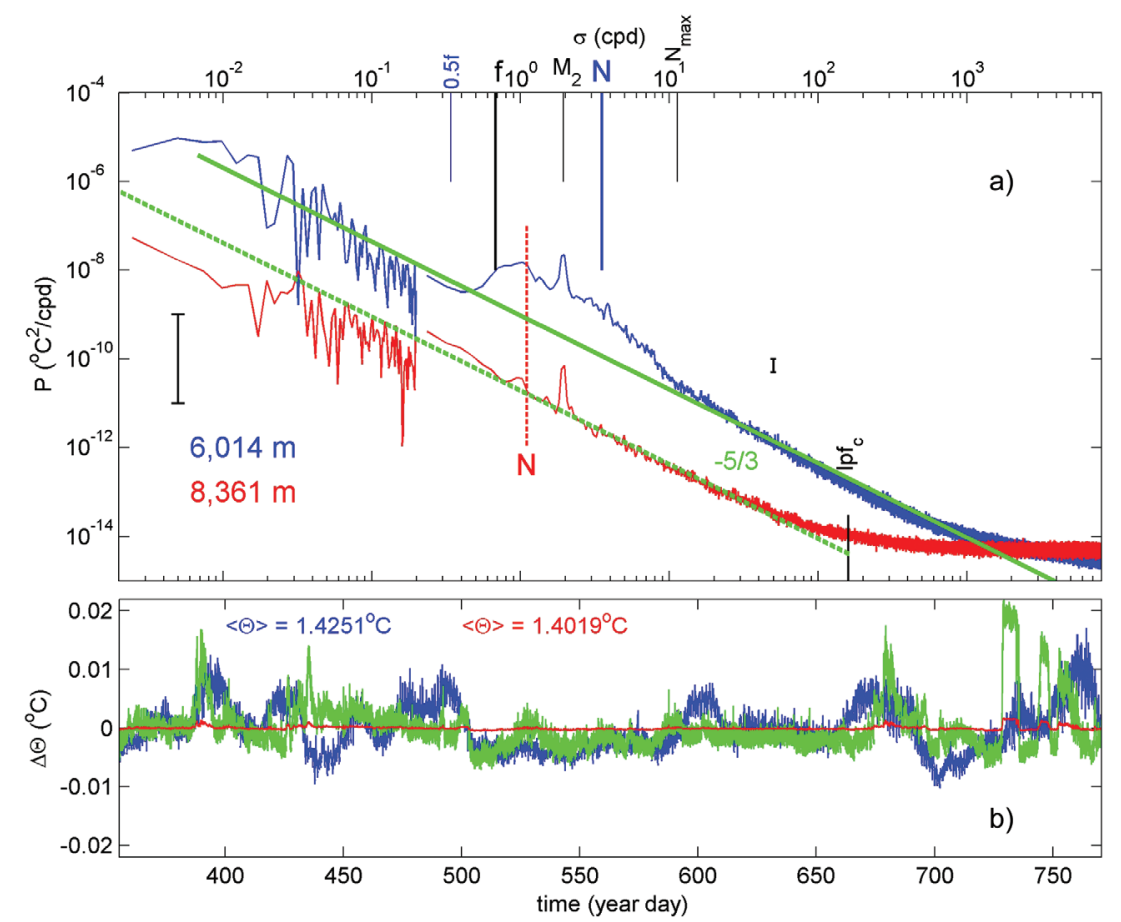

Figure 5. Conservative temperature from uppermost full good record of NIOZ4 sensors (UPP) at $6,014 \mathrm{~m}$ (blue) and deepest NIOZ3 sensors (LOW) at 8,361 m (red). (a) Spectra, weakly smoothed, $\sim 3$ degrees of freedom (dof) for $\sigma<0.2 \mathrm{cpd}$, and strongly smoothed, $\sim 100$ dof for $\sigma>0.2 \mathrm{cpd}$. The roll-off of the internal wave band is indicated by a maximum, probably small-scale buoyancy frequency $N_{\max }$. The inertial subrange falloff rate of $\sigma^{-5 / 3}$ is indicated by the straight green lines that are offset by a factor of 50 (in variance). The low-pass filter cutoff frequency for the LOW records is indicated by $\operatorname{lpf}_{c}$. (b) Time series of detrended (to remove drift), despiked (UPP), and lowpass-filtered (LOW) records of the spectra in panel (a), with (in green) the LOW record multiplied by a factor of 12.5 corresponding to ratio in standard deviation between the two records. The mean values are from the conductivity-temperature-depth data at the corresponding depth for UPP, and extrapolated for LOW.

inertial motions are small and vice versa (Fig. 4e). This is typical for ocean conditions with nonsmooth, small steplike varying stratification (van Haren 2006).

\section{c. A spectral comparison of temperature data from the upper and lower PRT}

The estimated decrease in stratification between 6,100 and $8,200 \mathrm{~m}$ as extrapolated from the lowest portion of the CTD data between 6,900 and 7,100 m amounts to a factor of 10 or a factor of 3 in $N$. This decrease is reflected in the variance of moored temperature observations (Fig. 5). As in Figure 3, two different degrees of smoothing are applied, below and above the transition frequency. 
At most frequencies in Figure 5(a) outside the horizontal white noise ranges, the UPP demonstrates 50 times more variance than the LOW, as may be inferred from the vertical distance between the green sloping lines. This is observed for subinertial frequencies in the range $0.05 \mathrm{cpd}<\sigma<0.5 f$ and for superbuoyancy frequencies $N_{\max }<\sigma<100 \mathrm{cpd}$ (noise roll-off). $N_{\max }$ denotes the maximum small, $2 \mathrm{~m}$ scale buoyancy frequency. Its value is equal to that of the maximum large-scale $N$ around 5,300 m near the top of the PRT, as determined from CTD observations (van Haren and Gostiaux 2016). In the UPP spectrum, it is the point where the enhanced IGW variance steeply slopes to the subinertial range. The superbuoyancy range basically consists of the inertial subrange of turbulence, as its slope is close to $\sigma^{-5 / 3}$. The small subinertial range fitting the same green slope is probably coincidental as it does not imply stratified turbulence. It is the frequency range of submesoscale variability. Also, the errors in this region of the spectra are larger, so the slope is less accurately determined.

There are two frequency ranges within which the two spectra differ by a factor of $125 \pm 25$ in variance. This is observed for the subinertial range $0.003<\sigma<0.05 \mathrm{cpd}$ and for the extended IGW band $0.9 f<\sigma<N_{\max }$. A small change in slope within the IGW occurs at $N$. Within the IGW, the LOW data do not show much elevation or change in slope extending in variance above that of the inertial subrange, except for the tides and a slope change for near-subinertial frequencies $\sigma<0.9 f$. For $\sigma=0.5 f$, the smallest variance difference of a factor of 40 is observed between the two spectra. These differences are consistent with the variance changes for very weakly stratified waters $N<4 f_{h}$ that were estimated to adopt the law $P_{w} \propto N^{+2}$ (van Haren 2015). Simply relating $w \propto(d T / d t) / N^{2}$ suggests that $P_{T} \propto N^{+4}$, or a factor of 100 change in variance because of changes in $N$. The interpretation by van Haren (2015) was that such a spectrum is dominated by gyroscopic nonequilibrium waves. It implies active turbulent overturning. The estimated mean buoyancy frequency equals $1 \mathrm{cpd}$ for LOW coinciding with the diurnal tide. The maximum variance difference by a factor of about 150 between the two spectra is found around $\sigma=0.01 \mathrm{cpd}$.

The spectral observations are reflected in the time series observations, which have roughly equal amplitudes when LOW data are multiplied by a factor of 12.5 to compare with UPP (Fig. 5b). Prior to plotting these data, UPP data are despiked and LOW data are low-pass filtered using the noise cutoff indicated in Figure 5(a). The two time series are detrended to correct for drift, and local mean CT values at each depth are added as inferred from CTD for UPP and as extrapolated from CTD for LOW. The trends correspond with the nominal drift of about $1 \mathrm{mK}$ per month. The minimal change in temperature of $<1 \mathrm{mK}$ between beginning and end of the UPP record reflects the negligible variation found between the 2013 and 2015 CTD observations around 6,100 m near the mooring site. From visual inspection of the two time series, which is dominated by the large 20 and $100 \mathrm{~d}$ variations, no correlation is found between them (at these periodicities). This is confirmed by a coherence spectrum (not shown), which gives a significant coherent signal at tidal frequencies only with an average $90^{\circ}(3 \mathrm{~h})$ phase difference for the entire record. As will be demonstrated in detailed timedepth series in Section 3d, this lack (except for the semidiurnal tide) of overall coherence 


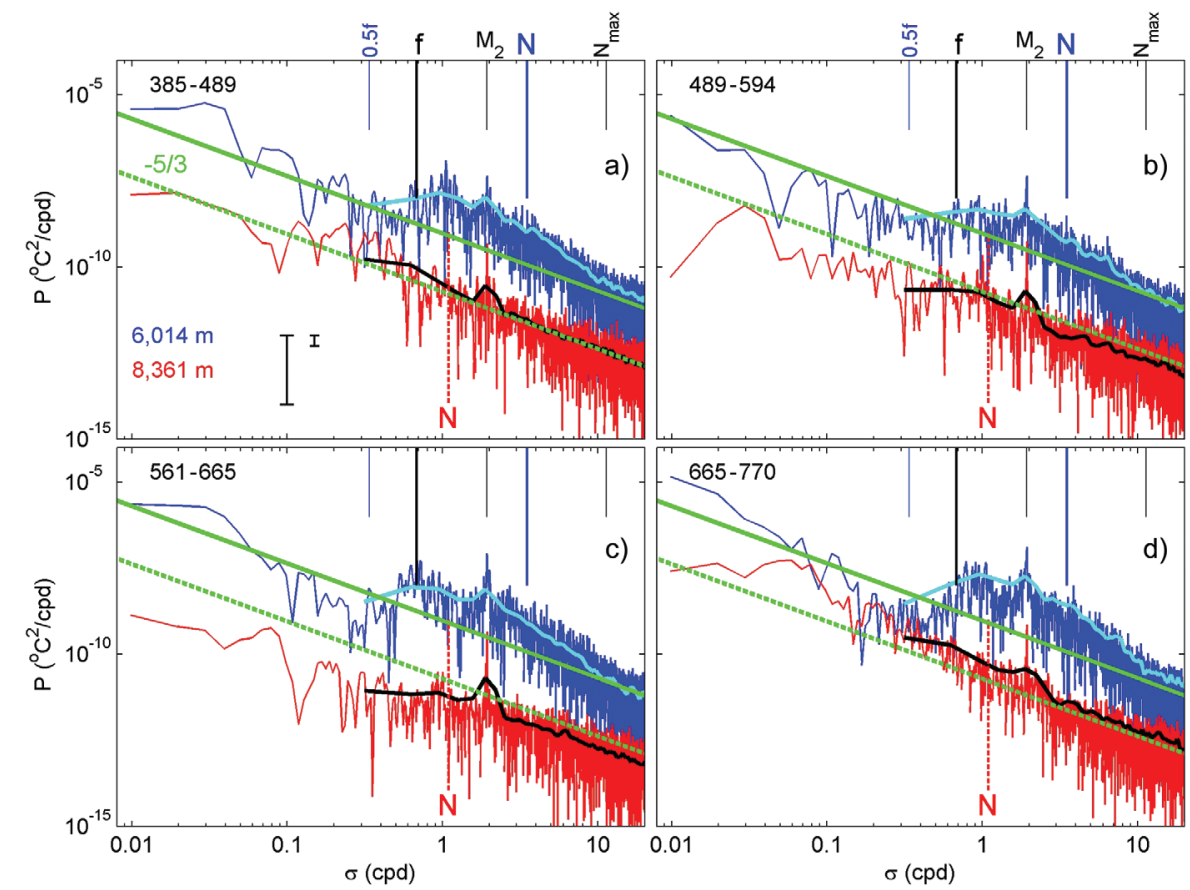

Figure 6. Spectra as in Figure 5(a), but for four subsections of $104 \mathrm{~d}$ records showing variability in inertio-gravity wave (IGW) and subinertial variance. Full weakly smoothed 3 degrees of freedom (dof) spectra are shown, with strongly smoothed 100 dof spectra in light blue and black for $\sigma>0.5 f$ only. The green lines indicating a $\sigma^{-5 / 3}$-slope are identical in all panels and can be used for guidance of changes in variance. (a) Modest turbulent period, with near-bottom variance enhancement between $0.1 \mathrm{cpd}$ and $f$. Year days range is indicated in the upper left corner. (b) Weakly turbulent period, with smaller variance in IGW and subinertial bands, compared with panel (a). (c) Weakest turbulent period. (d) Strongest turbulent period.

over the 2,100 m vertical distance is misleading for particular events or short periods of the observations.

The LOW time series show considerably more subinertial variability in the first $100 \mathrm{~d}$ and, in particular, in the last $100 \mathrm{~d}$ of observations. This is reflected in the sequence of spectra for $\sim 100 \mathrm{~d}$ records, the length needed for sufficient resolution and more or less consecutively chosen to demonstrate different turbulence regimes. This was achieved with only one month overlap somewhat arbitrarily chosen between periods 2 and 3 as the total length is $<400 \mathrm{~d}$ for the record starting with large variations at day 385 (Fig. 6). The green $\sigma^{-5 / 3}$ slopes are identical to the ones in Figure 5, for guidance. Both data sets show the largest variance in the first (Fig. 6a) and last (Fig. 6d) periods. This roughly coincides with times when the flow at $6,208 \mathrm{~m}$ is directed to the west, negative $u_{\mathrm{lf}}$ (Fig. 4c), with the notion that during the last segment only $25 \mathrm{~d}$ of current meter data are obtained. Larger 
Table 1. Vertical and time mean turbulence estimates for the observations in Figures 7-11. Estimates are only made for the NIOZ4 sensors (UPP) data between the range of [6,004 6,204] m. Averages are for $2 \mathrm{~d}$ periods, except for $4 \mathrm{~d}$ for Figure 9 and $0.52 \mathrm{~d}$ for Figure 11. The number of data points is the same for all periods. Averaging over the $200 \mathrm{~m}$ depth range is indicated by $\langle\ldots\rangle$, and over time by $[\ldots]$.

\begin{tabular}{ccrcc}
\hline Figure & Period (year days) & {$[<\varepsilon>]\left(\mathrm{m}^{2} \mathrm{~s}^{-3}\right)$} & {$\left[<K_{z}>\right]\left(\mathrm{m}^{2} \mathrm{~s}^{-1}\right)$} & {$[<N>]\left(\mathrm{s}^{-1}\right)$} \\
\hline 7 & $526-528$ & $6 \pm 4 \times 10^{-13}$ & $2 \pm 1 \times 10^{-6}$ & $2.4 \pm 0.3 \times 10^{-4}$ \\
8 & $429-431$ & $1.7 \pm 1 \times 10^{-10}$ & $6 \pm 3 \times 10^{-4}$ & $2.4 \pm 0.3 \times 10^{-4}$ \\
9 & $670-674$ & $6 \pm 4 \times 10^{-11}$ & $2 \pm 1 \times 10^{-4}$ & $2.5 \pm 0.3 \times 10^{-4}$ \\
10 & $754-756$ & $2 \pm 1.5 \times 10^{-10}$ & $7 \pm 3 \times 10^{-4}$ & $2.4 \pm 0.3 \times 10^{-4}$ \\
11 & $759.92-760.5$ & $7 \pm 4 \times 10^{-10}$ & $2 \pm 1 \times 10^{-3}$ & $2.5 \pm 0.3 \times 10^{-4}$ \\
\hline
\end{tabular}

variance is found not only in IGW, but also at subinertial and superbuoyancy frequencies. In addition, the first period shows some increased diurnal motions in UPP, whereas semidiurnal motions are relatively weak. For LOW, most pronounced variations by up to a factor of 100 are observed at subinertial frequencies. In particular, during the last period (Fig. 6d), motions around $\sigma=0.5 f$ are comparable in variance to those of UPP, while being only a factor of 5 less during the first period. During this first period, the LOW spectrum is enhanced between approximately $0.1<\sigma<0.5 \mathrm{cpd}$. During the last period, a broader range is enhanced, $0.03<\sigma<0.3 \mathrm{cpd}$, which may be extended to $2.5 \mathrm{cpd}$.

\section{d. Detailed temperature observations around 6,100 and 8,200 $\mathrm{m}$}

Five short periods are selected to be representative for the yearlong record (Fig. 4a and Table 1). Loose criteria are based on a variety of dissipation rates, and hence average temperatures and tidal and inertial kinetic energies. The variability is governed by the large-scale 20 and $100 \mathrm{~d}$ periodic modulations. The order of figures follows increasing mean temperature of UPP. In each figure, the temperature range is set around the mean value of the two records in Figure 5(b) for that time period. For UPP, variations in the mean buoyancy frequency around the local CTD value are also accounted for by computing them from reordered stably stratified data. This is not possible for LOW, so that only the mean extrapolated $N$ is used. The temperature ranges are fixed to $0.0125^{\circ} \mathrm{C}$ for UPP and $0.001^{\circ} \mathrm{C}$ for LOW, commensurate with the mean variance difference for the IGW band found in Figure 5(a).

During a relatively quiescent period, when mean temperatures around 6,100 m are relatively low, the internal wave height, clearly dominated by the semidiurnal tide, is about 50 $\mathrm{m}$ crest to trough in both data sets (Fig. 7) and seemingly decreasing to the bottom in the lower $50 \mathrm{~m}$. The mean stratification for UPP, measured from the number of isotherms, is on average $6 \mathrm{mK}$ over $200 \mathrm{~m}$, and the isotherms are relatively smooth, in accordance with the low mean dissipation rate (Table 1). Although the LOW data show approximately equal tidal amplitude in comparison with UPP, they show more high-frequency motions (e.g.,

Table 1 


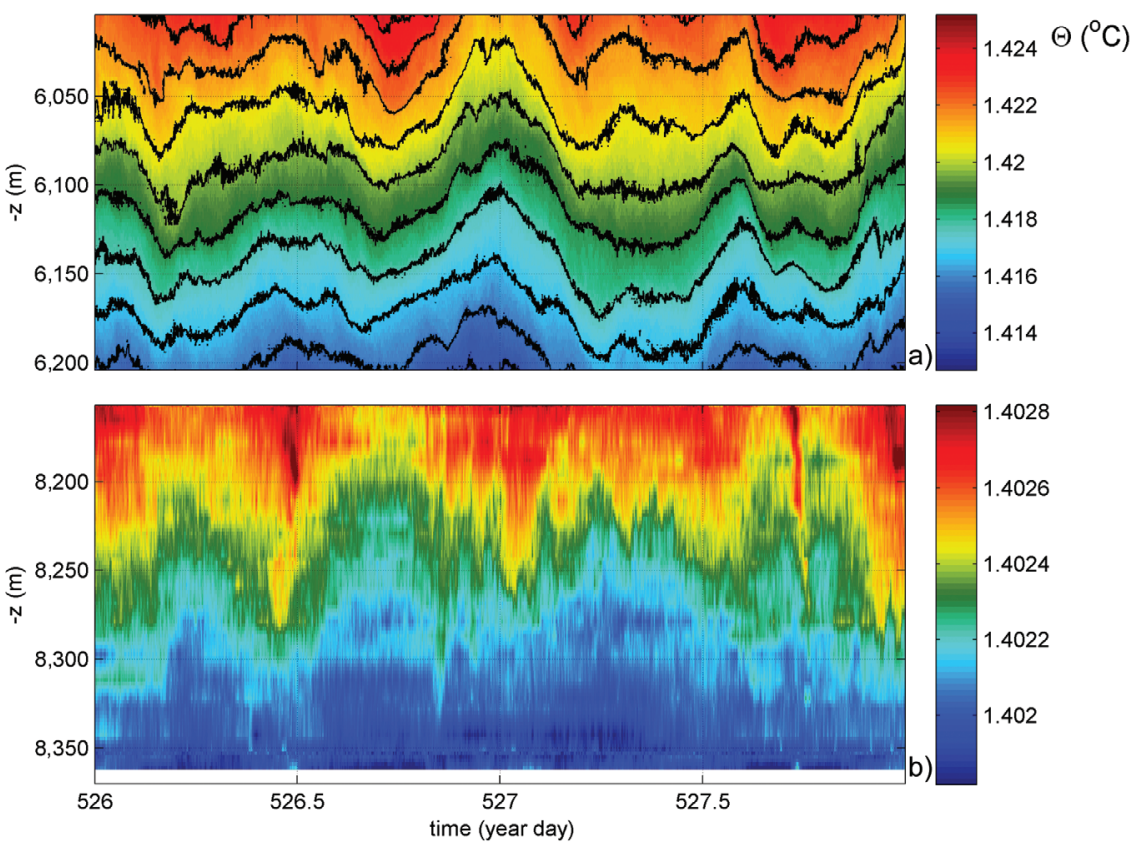

Figure 7. Two days of detailed time-depth series typical for a quiescent period; see Table 1 for turbulence estimates for NIOZ4 sensors (UPP), dominated by $\mathrm{M}_{2}$ tides and a phase difference of about $6 \mathrm{~h}$ or an apparent mode 2 across the 2,000 $\mathrm{m}$ between the two data sets. The vertical scale is identical for the two panels, so that the lower one is slightly taller as it ranges $213 \mathrm{~m}$ and includes a blanking toward the Puerto Rico Trench floor. (a) Upper array of UPP sensors with black contour intervals every $1 \mathrm{mK}$. (b) Lower array of NIOZ3 sensors (LOW), low-pass-filtered and heavily interpolated data. The color scale is a factor of 1/12.5 times the range in panel (a).

Figure 8

Figure 9 around day 527) and possibly stronger overturning around day 527.7. There is a strong phase difference of about $6 \mathrm{~h}$ in the tidal motions between UPP and LOW, or complete out of phase resembling a quasi-mode- 2 motion, over a 2,000 m distance. It suggests a slow vertical phase speed of approximately $0.09 \mathrm{~m} \mathrm{~s}^{-1}$.

With larger turbulence and warmer temperatures, the IGW amplitudes increase up to $100 \mathrm{~m}$ crest to trough in both data sets (Fig. 8). This example shows a mix of inertial (1.5 d), diurnal, semidiurnal, and fourth-diurnal motions. The latter are indistinguishable from the buoyancy period. There are eight isotherms in UPP, on average, and they show more variability in slope steepness than in Figure 7. Apparent overturning is also visible in LOW, in the formation of fingering, throughout the time span but largest after day 430.

Warmer still but having about one-third of the turbulence in Figure 8, a period of combined inertial and semidiurnal tidal motions is presented in Figure 9. In UPP, the modulation of tidal motions by inertial motions generates amplitudes varying from $20 \mathrm{~m}$ to $100 \mathrm{~m}$. In LOW, the amplitude variation is smaller, but larger than in Figure 7. Vertical phase differences 


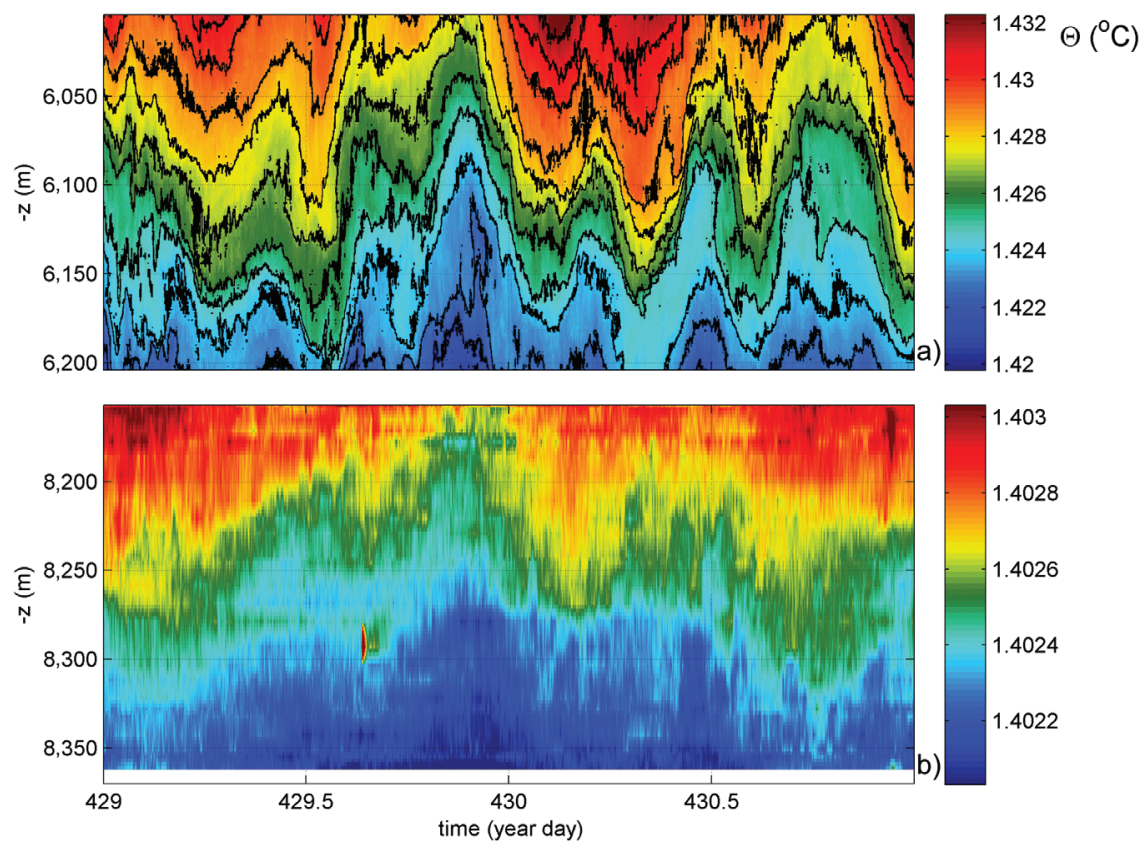

Figure 8. As in Figure 7, but for a relatively strongly turbulent period of mixed $\mathrm{K}_{1}$ and $\mathrm{M}_{2}$ tidal motions and varying vertical phase differences between the two data sets. The color ranges are shifted commensurate with the changes in mean temperature for the given periods.

between the two data sets vary with time, from almost zero around day 672 to $2-3 \mathrm{~h}$ (e.g., on day 673-673.5).

In the warmest and strong turbulence waters with clear overturns appearing in both UPP and LOW, the vertical phase difference is negligible over 2,000 $\mathrm{m}$ (Fig. 10). This apparent local mode 1, or large vertical phase speed behavior, of a mixture of diurnal and semidiurnal internal tides also includes short-period motions around day 755.1. These have a period of about $2 \mathrm{~h}$, or a frequency close to $N_{\max }$ in Figure 5(a). It is noted that these motions also appear in LOW, but possibly less frequently as they do not show in the spectra of the deepest LOW sensor in Figures 5(a) and 6(d). In the period of Figure 10, they have $>50 \mathrm{~m}$ crest-totrough amplitudes in LOW. The tidal modulation generates isotherm excursions exceeding the $200 \mathrm{~m}$ range of observations in UPP.

A further detailed example of a strongly turbulent semidiurnal period shows a mixture of convective and $50 \mathrm{~m}$ shear-induced overturning in both data sets (Fig. 11). From these highly nonlinear "waves," a vertical phase difference is somewhat hard to establish. The first part of the main turbulent, warmer water influx from above seems to occur 2-3 h earlier in UPP than in LOW around day 760.2, while the second part seems in phase around day 760.32 .

Figure 10 

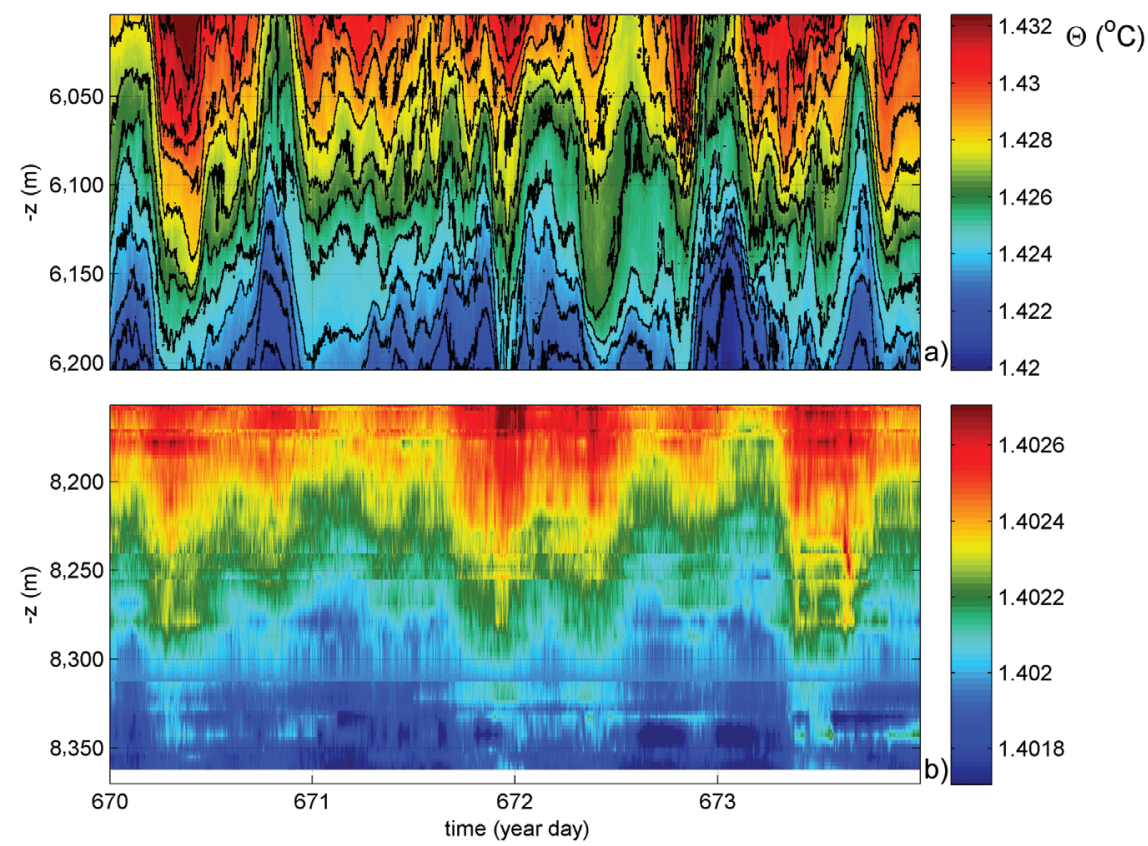

Figure 9. As in Figure 8, but for a 4 d period of relatively moderate turbulence of mixed $f$ and $\mathrm{M}_{2}$ motions and small vertical phase differences between the two data sets.

\section{Discussion and conclusions}

The observed changes in turbulence levels for UPP show that deep PRT waters vary from quiescent to relatively strongly turbulent up to values comparable with and, in terms of diffusivity, exceeding those of the open ocean (e.g., Gregg 1989). Although turbulence estimates could not be made from the poorly resolving near-bottom instruments, the correspondence with the instrumentation near the top of the PRT suggests likewise variations near the bottom.

The weakest turbulence is found when the phase difference of the main semidiurnal motions is large between the two data sets. This low vertical phase speed occurs when mean temperatures are low relatively to the record mean, at the trough of the large-scale 20 and $100 \mathrm{~d}$ variations.

The largest turbulence is found when the phase difference between the dominant tidal internal wave motions is minimal over the 2,000 $\mathrm{m}$ range. Then, the largest internal wave amplitudes are found, with those around $6,100 \mathrm{~m}$ exceeding the ones around $8,200 \mathrm{~m}$. This high vertical phase speed occurs when waters are warm(ing), when the large-scale 20 and $100 \mathrm{~d}$ periodic motions are at or nearing a crest. These large-scale subinertial periodic motions are not correlated or coupled over the $2,000 \mathrm{~m}$. They are found to be most energetic 


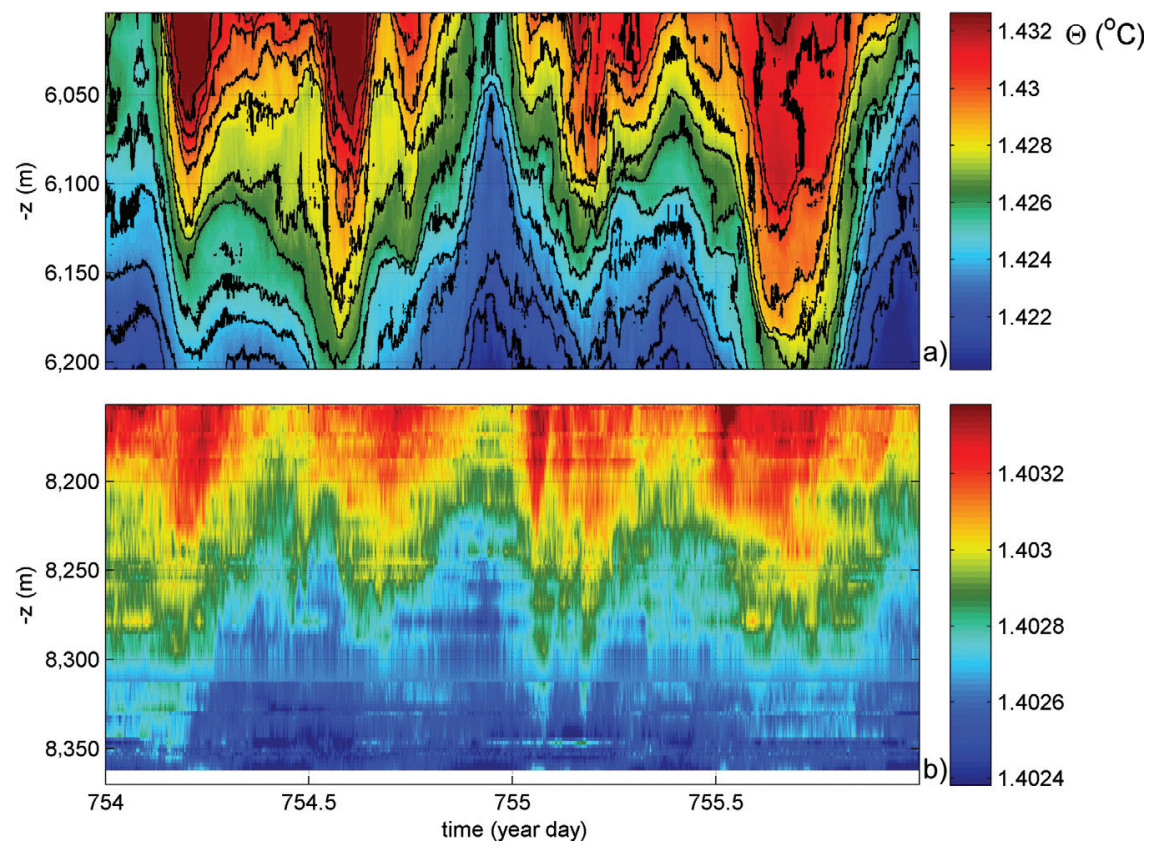

Figure 10. As in Figure 8, but for a relatively strongly turbulent period of dominant $\mathrm{M}_{2}$ tidal motions and small vertical phase differences between the two data sets.

around 6,100 m. High temperatures sometimes, but not always, coincide with periods of relatively large inertial motions.

Although the Milwaukee Deep is the deepest PRT point, shear-induced turbulence following the large-scale flow plunging into the deep from a sill like in the RFZ (Polzin et al. 1996; Ferron et al. 1998) is not expected in the present observations. This is because the mooring is on a flat bottom relatively far $(\sim 30 \mathrm{~km})$ from the nearest and small $(<300 \mathrm{~m}$ high $)$ sill. Its effects would not show in the measurements around $6,000 \mathrm{~m}$. This is reflected in the high-resolution temperature observations, which do not show chains of Kelvin-Helmholtz billows evidencing shear-induced turbulence as in similar RFZ data (van Haren et al. 2014). Instead, UPP observations show mostly convective mixing, with secondary shear-induced instabilities (van Haren and Gostiaux 2016). It was suggested that the interaction between tidal and inertial motions resulted in convective mixing induced by internal waves in a slantwise direction, given the weak stratification and $0.01-0.02 \mathrm{~m} \mathrm{~s}^{-1}$ current speeds, as observed. Here, those IGW observations are extended across 2,000 $\mathrm{m}$ vertically, toward the seafloor.

The weak stratification varying by a factor of about 10 between $6,100 \mathrm{~m}$ and the bottom results in potential trapping of subinertial IGW, $0.5 f<\sigma<0.9 f$. This band shows the smallest variance difference between the two data sets, being near-equal during short periods 

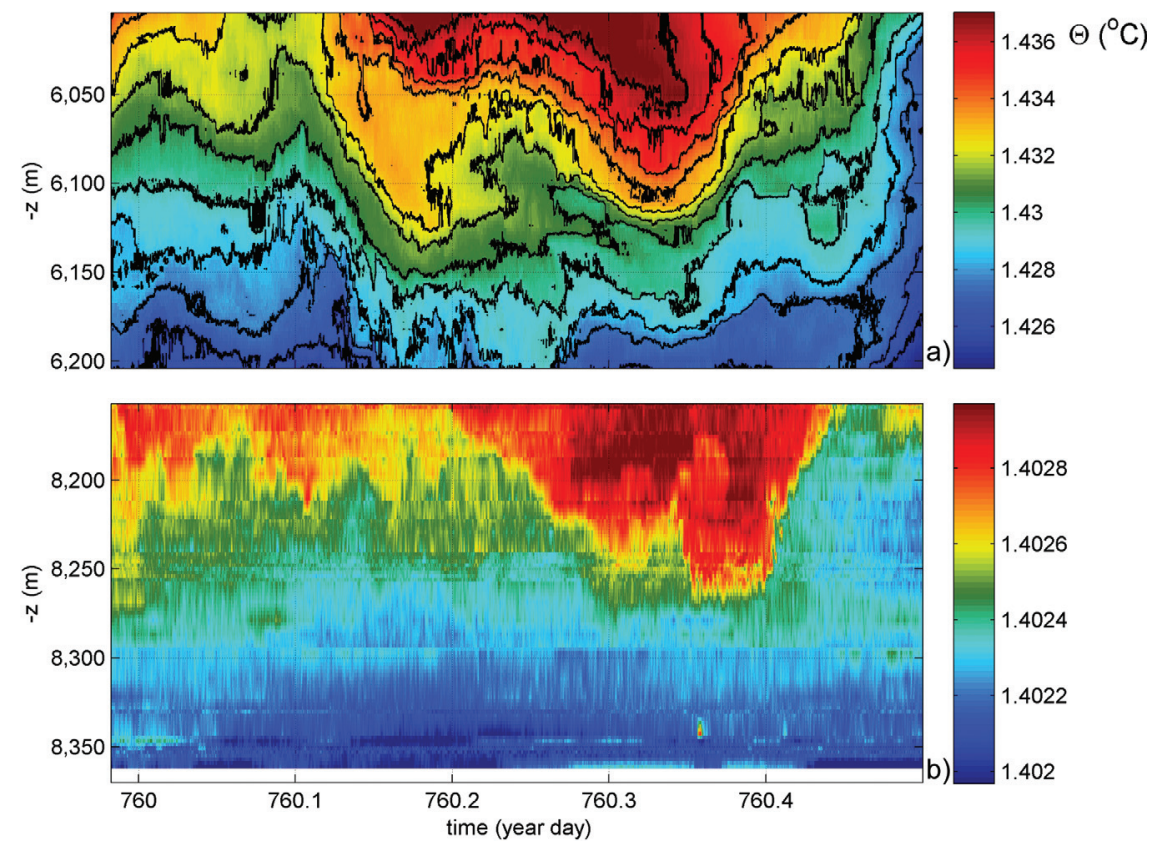

Figure 11. As in Figure 8, but for a single $\mathrm{M}_{2}$ tidal period of relatively strong turbulence, visible in both data sets. The vertical phase difference is difficult to establish but seems about $1 \mathrm{~h}$, the upper set leading.

of time like near the end of the record. Then, this band even extends to lower frequencies, for LOW, whereas at UPP the highest turbulence values are observed.

The previous discussion does not imply that one would expect such near-bottom mixing to also occur above a flat bottom of an open-ocean basin. Although the internal wave mixing seems to be locally induced, rather than being transported isopycnally from the topography into the interior, the horizontal boundaries are expected to generate meridionally propagating internal waves. It is noted that this is mainly expected for near-inertial waves as mean bottom slopes are considerably smaller than semidiurnal frequency internal wave slopes. Horizontal boundaries also support boundary currents, in the upper layers guiding the Antilles Current, with the NADW flowing in reverse direction. These flows are in shallower waters than the PRT, the horizontal boundaries of which basically only guide AABW that can have slightly different characteristics, presumably because of spatially varying mixing. The present largescale subinertial 20 and $100 \mathrm{~d}$ periodic fluctuations in AABW suggest a vertical coupling between these different waters, all meandering because of baroclinic instabilities and not evidencing a dominant barotropic coupling. The AABW periodicities are similar to the 20 and $100 \mathrm{~d}$ periodicities observed in NADW by Lee et al. (1990), with the $20 \mathrm{~d}$ periodicity also in the zonal current component mainly. As the present observations are from 6,100 
$\mathrm{m}$ instead of 2,000-4,000 $\mathrm{m}$, these meanders or eddies have a very large-scale baroclinic character that is independent of the flow direction being either southeastward for depths shallower than 4,500 $\mathrm{m}$ or (north-)eastward for depths greater than 4,500 $\mathrm{m}$ for the PRT AABW-transporting flow.

Although the present observations are from a single mooring site, little evidence is found for AABW flowing along the northern wall and NADW along the southern wall, as suggested by Tucholke (2002). The horizontal differences observed in the 2013 CTD profiles are too small for NADW to be characterized. Instead, they demonstrate small variability in AABW characteristics, which is evidence of active mixing of varying intensity across the basin and with time. With the heat being mixed down from overlying NADW above, increased $\mathrm{AABW}$ temperatures are a tracer for larger turbulent heat transport and, here, internal wave activity. With increased heat transport, suspended material will be more intensely mixed to supply bottom life when AABW temperatures are increased. In between relatively turbulent periods, quiescent periods may last for weeks to months with little turbulent exchange at rates of only about one order of magnitude above molecular levels.

Acknowledgments. The captain and crew of the R/V Pelagia are thanked for the pleasant cooperation during the sea operations. I greatly thank M. Laan and L. Gostiaux for their collaboration in design and construction of NIOZ temperature sensors, hardware and software, and many discussions. The construction of the NIOZ temperature sensors has been financed in part by NWO, the Netherlands Organization for the Advancement of Scientific Research.

\section{REFERENCES}

Bryan, F. O., C. W. Böning, and W. R. Holland. 1995. On midlatitude circulation in a highresolution model of the North Atlantic. J. Phys. Oceanogr., 25, 289-305. doi: 10.1175/15200485(1995)025\%3C0289:OTMCIA\%3E2.0.CO;2

Dillon, T. M. 1982. Vertical overturns: A comparison of Thorpe and Ozmidov length scales. J. Geophys. Res.: Oceans, 87, 9601-9613. doi: 10.1029/JC087iC12p09601

Eriksen, C. C. 1982. Observations of internal wave reflection off sloping bottoms. J. Geophys. Res.: Oceans, 87, 525-538. doi: 10.1029/JC087iC01p00525

Ferron, B., H. Mercier, K. Speer, A. Gargett, and K. Polzin. 1998. Mixing in the Romanche Fracture Zone. J. Phys. Oceanogr., 28, 1929-1945. doi: 10.1175/1520-0485(1998)028\%3C1929: MITRFZ\%3E2.0.CO;2

Gerkema, T., J. T. F. Zimmerman, L. R. M. Maas, and H. van Haren. 2008. Geophysical and astrophysical fluid dynamics beyond the traditional approximation. Rev. Geophys., 46, RG2004. doi: 10.1029/2006RG000220

Gregg, M. C. 1989. Scaling turbulent dissipation in the thermocline. J. Geophys. Res.: Oceans, 94, 9686-9698. doi: 10.1029/JC094iC07p09686

Intergovernmental Oceanographic Commission (IOC), Scientific Committee on Oceanic Research, and International Association for the Physical Sciences of the Oceans. 2010. The International Thermodynamic Equation of Seawater - 2010: Calculation and Use of Thermodynamic Properties. IOC, Manuals and Guides No. 56. Paris: UNESCO, 196 pp.

Kunze, E. 1985. Near-inertial wave propagation in geostrophic shear. J. Phys. Oceanogr., 15, 544-565. doi: 10.1175/1520-0485(1985)015\%3C0544:NIWPIG\%3E2.0.CO;2 
LeBlond, P. H., and L. A. Mysak. 1978. Waves in the Ocean. New York: Elsevier, 602 pp.

Lee, T. N., W. Johns, F. Schott, and R. Zantopp. 1990. Western Boundary Current structure and variability east of Abaco, Bahamas at $26.5^{\circ}$ N. J. Phys. Oceanogr., 20, 446-466. doi: 10.1175/15200485(1990)020\%3C0446:WBCSAV\%3E2.0.CO;2

Mantyla, A. W., and J. L. Reid. 1983. Abyssal characteristics of the World Ocean waters. Deep-Sea Res., Part A, 30, 805-833. doi: 10.1016/0198-0149(83)90002-X

Mercier, H., and K. G. Speer. 1998. Transport of bottom water in the Romanche Fracture Zone and the Chain Fracture Zone. J. Phys. Oceanogr., 28, 779-790. doi: 10.1175/15200485(1998)028\%3C0779:TOBWIT\%3E2.0.CO;2

Millot, C., M. Benzohra, and I. Taupier-Letage. 1997. Circulation off Algeria inferred from the Médiprod-5 current meters. Deep Sea Res., Part I, 44, 1467-1495. doi: 10.1016/S09670637(97)00016-2

Oakey, N. S. 1982. Determination of the rate of dissipation of turbulent energy from simultaneous temperature and velocity shear microstructure measurements. J. Phys. Oceanogr., 12, 256-271. doi: 10.1175/1520-0485(1982)012\%3C0256:DOTROD\%3E2.0.CO;2

Obaton, D., C. Millot, G. Chabert D'Hières, and I. Taupier-Letage. 2000. The Algerian current: Comparisons between in situ and laboratory data sets. Deep Sea Res., Part I, 47, 2159-2190. doi: 10.1016/S0967-0637(00)00014-5

Orlanski, I., and K. Bryan. 1969. Formation of the thermocline step structure by large-amplitude internal gravity waves. J. Geophys. Res., 74, 6975-6983. doi: 10.1029/JC074i028p06975

Osborn, T. R. 1980. Estimates of the local rate of vertical diffusion from dissipation measurements. J. Phys. Oceanogr., 10, 83-89. doi: 10.1175/1520-0485(1980)010\%3C0083:EOTLRO\%3E2.0.CO;2

Polzin, K. L., K. G. Speer, J. M. Toole, and R. W. Schmitt. 1996. Intense mixing of Antarctic Bottom Water in the equatorial Atlantic Ocean. Nature, 380, 54-57. doi: 10.1038/380054a0

Rhein, M., L. Stramma, and G. Krahmann. 1998. The spreading of Antarctic Bottom Water in the tropical Atlantic. Deep Sea Res., Part I, 45, 507-527. doi: 10.1016/S0967-0637(97)00030-7

Smith, W. H. F., and D. T. Sandwell. 1997. Global sea floor topography from satellite altimetry and ship depth soundings. Science, 277, 1956-1962. doi: 10.1126/science.277.5334.1956

Thorpe, S. A. 1977. Turbulence and mixing in a Scottish loch. Philos. Trans. R. Soc., A, 286, 125-181. doi: 10.1098/rsta.1977.0112

Thorpe, S. A., 1987. Transitional phenomena and the development of turbulence in stratified fluids: A review. J. Geophys. Res.: Oceans, 92, 5231-5248. doi: 10.1029/JC092iC05p05231

Tucholke, B. E. 2002. The Greater Antilles Outer Ridge: Development of a distal sedimentary drift by deposition of fine-grained contourites, in Deep-Water Contourite Systems: Modern Drifts and Ancient Series, Seismic and Sedimentary Characteristics, D. A. V. Stow, C. J. Pudsey, J. A. Howe, J.-C. Faugères, and A. R. Viana, eds. Geological Society Memoir 22. London: Geological Society, pp. 39-55.

van Haren, H. 2006. Asymmetric vertical internal wave propagation. Geophys. Res. Lett., 33, L06618. doi: 10.1029/2005GL025499

van Haren, H. 2015. A composite vertical current spectrum for strongly and weakly stratified seas and oceans. J. Mar. Res., 73, 33-48. doi: 10.1357/002224015815782670

van Haren, H., and L. Gostiaux. 2016. Convective mixing by internal waves in the Puerto Rico Trench. J. Mar. Res., 74, 161-173. doi: 10.1357/002224016819594809

van Haren, H., L. Gostiaux, E. Morozov, and R. Tarakanov. 2014. Extremely long KelvinHelmholtz billow trains in the Romanche Fracture Zone. Geophys Res. Lett., 41, 8445-8451. doi: 10.1002/2014GL062421 
van Haren, H., M. Laan, D.-J. Buijsman, L. Gostiaux, M. G. Smit, and E. Keijzer. 2009. NIOZ3 Independent temperature sensors sampling yearlong data at a rate of $1 \mathrm{~Hz}$. IEEE J. Oceanic Eng., 34, 315-322. doi: 10.1109/JOE.2009.2021237

van Haren, H., and C. Millot. 2004. Rectilinear and circular inertial motions in the Western Mediterranean Sea. Deep Sea Res., Part I, 51, 1441-1455. doi: 10.1016/j.dsr.2004.07.009

Received: 09 January 2017; revised: 31 May 2017. 


\section{Author Queries}

AQ1: Please check/approve the short title for the article.

AQ2: Please revise this sentence for clarity. There seems to be a transition missing between "we elaborate on the interaction between the boundary" and the continuation of the sentence "AABW-transporting current..."

AQ3: Does edit preserve your intent here? ("between the ranges of")

AQ4: van Haren and Gostiaux 2012 is cited in text but has not been included in the References; please provide a full citation.

AQ5: Does edit preserve your intent here? ("LOW data")

AQ6: Do edits preserve your intent here? ("UPP data are despiked and LOW data are low-pass filtered")

AQ7: Does edit preserve your intent here? ("NADW" rather than "NABW")

AQ8: Please revise "PRT - AABW-transporting flow" for clarity (it's not clear what the dash indicates; please replace the dash with written text).

AQ9: Does edit preserve your intent? [(“Figures 7-11 (F7-F11)"]. 